\title{
Establishment Decision of Experience Stores: Insights into Marketing Effect
}

\author{
Chi Chiang \\ Department of Management Science, National Chiao Tung University \\ 1001, Ta Hsueh Road, Hsinchu 300, Taiwan, R.O.C.
}

Tel: 886-3-5712121 ext. 57166 E-mail: cchiang@mail.nctu.edu.tw

\author{
Tsui-Yii Shih (Corresponding author) \\ Department of International Business, National Taipei University of Business
}

No. 321, Sec. 1, Jinan Rd., Zhongzheng District, Taipei City 100, Taiwan, R.O.C.

Tel: 886-2-23226535 E-mail: trace@ms16.hinet.net

Received: July 24, 2014 Accepted: October 18, $2014 \quad$ Published: October 20, 2014

doi:10.5296/jsss.v2i1.6471 URL: http://dx.doi.org/10.5296/jsss.v2i1.6471

\begin{abstract}
Methods of contacting customers are constantly evolving. An increasing number of manufacturers have established experience stores, plazas or centers that provide marketing, education, and trade functions to enhance business performance. This paper develops integer programming models to analyze the experience store establishment decision. Demand functions, cost parameters, and firm learning curves that impact on the experience store decision are also examined. In addition, this paper provides two case studies to validate the proposed experience store establishment models. Three proposed models can assist managers in developing marketing strategies related to the experience store establishment.
\end{abstract}

Keywords: Experience stores, Integer programming, Marketing

\section{Introduction}

More companies are spending less of their marketing budgets on traditional media, preferring to employ other marketing tools instead. One new marketing tool that many firms have used is the "experience store". These stores are designed to teach consumers how to use merchandises, or let consumers experience manufacturing process and business philosophy. 
For example, Amway, a global leader in multi-level marketing, has combined the functions of the logistics center, production process, and customer experiential service to establish experience centers worldwide. Similarly, AT\&T experience stores offer consumers a one-stop shop for all their information technology and entertainment connectivity needs. In this study, the definition or function of an experience store include a general showroom supplying the product information, and is also a place where the shopper can experience and buy the products. Experience stores not only benefit manufacturers' consumer experience programs, but also enhance trade and exhibition functions and the branding image of firms.

Related to the issue of the experience store establishment is the retail location decision. Numerous scholars have developed retail location theories and models to help managers decide on the retail location. In particular, the gravity model and retail attraction theory with many consumers and suppliers have been studied (Huff, 1964; Roy \& Thill, 2004; Santos-Peñate, Suárez-Vega, \& Dorta-González, 2007); they are used to explain the behavior of these groups, and are thus appropriate as a partial theory base for the experience store establishment decision. Moreover, scholars have derived some marketing or advertising models which indicate that marketing activities have an important effect on sales, especially through media choices (Kaufman \& Rangan, 1990; Schneider, Johnson, Sleeper, \& Rodgers, 1998; Farias, Aguiar, \& Melo 2014). Though consumers learn more about products in an experience store, the advertising concept and marketing effect are similar to those media such as television or newspaper ads. Finally, the mathematical optimization models have been used in the retail location analysis. In particular, the non-linearity assumption and/or zero-one variables are often employed (Reilly, 1931). In this study, we apply integer programming to formulate the experience store establishment decision.

The objective of this study is to use integer programming to investigate the experience store establishment decision and allow manufacturers to evaluate its marketing effect. This study will contribute to the marketing literature through the proposed experience store establishment models. This paper is organized as follows. Section 2 discusses the development and application of location models and the marketing perspectives on experience stores. Section 3 states the model assumptions and notations, and derives three integer programming models. Section 4 provides two case studies. Finally, section 5 concludes this paper.

\section{Theoretical Background and Application}

The retail location theories and marketing perspectives on experience stores are relevant to this study. We provide a brief literature review below.

\subsection{Retail Location Theories and Models}

It is important for a firm to think of the location strategy for its long-term development. Important retail location theories and models discussed by scholars include the land value theory (Haig, 1926), the spatial interaction theory (Roy \& Thill, 2004), and the market area model (Dasci \& Laporte, 2005). In short, these retail location theories emphasize the importance of specific sites, market area size, space, nature, population, distance, and 
attractiveness in the retail location decision. There are also construction methods for location decision which include the gravity model (Reilly, 1931; Huff, 1964), the portfolio location model (Mahajan, Sharma, \& Srinivas, 1985), regression methods and location-allocation models (Timor \& Sipahi, 2005). Another method, the judgmental approach (Blattberg \& Hoch, 1990), has been successfully applied to location decision, advertising budget allocation and marketing mix planning (Urban, 1970; Durvasula, Sharma, \& Craig, 1992; Küçükaydin, Aras, \& Altinel, 2011).

Of the above location theories and models, we consider the gravity model as being appropriate for planning the establishment of experience stores for a manufacturing firm. In Reilly's model (1931), consumers shopped a retail store closer to home without knowing any advantage of other alternative stores. Huff (1964), Bell et al. (1998), and Taylor et al. (2006) further examined some additional attraction factors that can induce consumers to travel further. In Huff's (1964) and Santos-Peñate et al.'s model (2007), attraction aij perceived by customers located at node vi towards a facility sited at $x_{j}$, is inversely proportional to a power of the distance between $v_{i}$ and $x_{j}$. Spatial interaction models, which can be grouped under the generic heading "gravity models," concern the process whereby entities at different points in physical space make contact, make demand/supply decisions, or make location choices (Roy et al., 2004). Aboolian, Berman and Krass (2007) considered a spatial interaction model for locating a set of new facilities that compete for customer demand with each other. The contribution of their work is the study of a discrete facility location problem with concave (non-decreasing) demand and presence of market expansion, and the development of efficient solution techniques which are applicable to a class of linear separable integer programming problems.

In this study, experience stores built by a firm, which provide full-line branding products, are considered to have higher attractiveness to consumers in comparison to general retailer stores. Also, once experience store attractiveness is determined, it can be used in the model. The above gravity models and retail attraction theory reviewed provide a partial theoretical basis for a firm to analyze its experience store establishment decision.

\subsection{Marketing Perspectives on Experience Stores}

In addition to acting as a marketing medium like general retail stores, experience stores can provide experiential marketing and values. Pine and Gilmore (1999), and Petkus (2004) outlined six key steps of experience marketing, and Mathwicka et al. (2002) suggested that experiential value perceptions are based upon interactions involving either direct usage or distanced appreciation of goods and services. Educational and knowledge transmission features are the major experiential values of experience stores. Firms usually use advanced information technologies and interactive services in experience stores to elaborate on the history of the company, introduce the usage methods of products, exhibit the manufacturing process, and solve consumer queries with professional product knowledge. In this way they obtain consumer confidence or product testing interest, and thereby increase sales and profits.

An experience store can carry multiple distinct product lines, while advertising usually promotes either a small number of product lines or an overall brand image. In practice, 
experience stores not only play a sales role, but are also expected to be an effective advertising medium and marketing promotion tool. The best location will maximize the firms' financial performance net of the additional investment in advertising (Schneider, Johnson, Sleeper, \& Rodgers, 1998). A good location with vivid features creates a "brand demand" effect, as well as "system attractiveness or relative preference for the brand" (Kaufman \& Rangan, 1990). Moreover, brand trust and brand effect lead to more brand outcomes, such as a higher sales-to-advertising ratio (Chaudhuri \& Holbrook, 2002). In academia, Ghosh, McLafferty and Craig (1995) discussed computational difficulties associated with competitive location problems under the assumption of discrete demand. Vilcassim et al. (1999), assuming a linear and separable demand function, built a demand-cost model with production and advertising costs, and discussed the nature of firm interaction with customers through some conduct parameters.

The most commonly used function for representing a downward-sloping price $(p)$ versus demand $(d)$ relationship is of the linear form $(d=a-b p)$. This function is introduced in many standard economics textbooks. Tellis (1988) conducted a meta-analysis study of models estimating the price elasticity of demand for various products and found that the mean price elasticity of demand is significantly negative. Also, Brodie and Kluyver (1984), Ghosh et al. (1984), Naert and Weverbergh (1981) and Gaur and Fisher (2005) investigated price elasticity issues using different datasets and pricing models. Besides cost-based and market-based pricing methods, market experiments can serve as useful scientific tools for firms to get a better understanding of consumer response to the use of marketing activities such as pricing and promotions, as well as new demand functions after the establishment of experience stores.

Therefore, based on the gravity model, retail attraction theory and marketing perspectives, we suggest a decision variable, the "number of experience stores established by a manufacturing firm," in our models. We suppose that the establishment of experience stores will have the marketing effect of attracting potential consumers. The demand curve of a firm incorporated with the decision variable of the number of experience stores established is a concave function. If firms can estimate their demand functions and the effect of experience stores on sales, and solve the proposed models, then the maximum profit may be obtained.

Our models also take into account the learning curve associated with the cost of operating an experience store. The original use of learning curves was to help predict the reduction in costs as the number of units produced rose (Chamber \& Johnston 2000). By combining the effect of various factors (e.g., labor learning and efficiency), managers can decrease unit cost and thereby reduce prices. As such, in this study, we assume that the greater the number of experience stores established, the greater the accumulation of management experiences, and the greater the cost reduction for subsequent store operations.

\section{Models and Notations}

We make two assumptions before developing models. First, firms can estimate the demand function of a product that is assumed to be linear (before the establishment of experience stores) and additive in the number of experience stores (considering the attractive and 
marketing effects). Second, too many experience stores will decrease the marginal utility of the marketing effect, thus causing a limited increase on sales volume. Hence, the additional sale volume created via experience stores will be expressed using a concave function (as described in section 1). The notations used in the models are as follows.

\section{Model Parameters}

$D_{\text {oij }} \quad$ Estimated original demand volume of branding product $j$ in region $i$.

$D_{a i j} \quad$ Estimated demand volume of branding product $j$ after setting experience stores in region $i$.

$T F C_{i} \quad$ Estimated cost of establishing one experience store in region $i$.

$T F C_{i k} \quad$ Estimated cost of establishing $k^{\text {th }}$ experience store in region $i$.

$E T C_{i} \quad$ The store design, interior cost, and education and training costs in region $i$.

$U C_{j} \quad$ Unit cost of branding product $j$ of a firm.

$\alpha_{i} \quad$ Cost of establishing the first experience store in region $i$.

$\beta_{i} \quad$ Parameter measuring the rate of the decrease in establishment cost as more experience stores are built in region $i$.

$b_{1 i j}, b_{2 i j} \quad$ Demand function coefficients of branding product $j$ in region $i$ measured by a firm. $\mathrm{b}_{1 i j}$ and $\mathrm{b}_{2 i j}$ are assumed to be greater than zero.

$c_{1 i j}, c_{2 i j} \quad$ Coefficients for the number of experience stores in $D_{a i j}$, which are measured by a firm. $c_{1 i j}$ and $c_{2 i j}$ are assumed to be greater than zero.

$r_{i} \quad$ The largest possible number of experience stores established for branding products in region $i . r_{i}$ is equal to the integral part of the minimum value of $c_{1 i j} / 2 c_{2 i j}$ (over $j$ ) in region $i$.

$m \quad$ Number of regions considered by a firm.

$n \quad$ Number of branding products provided for sales by a firm.

Decision variables

$P_{i j} \quad$ Product price of branding product $j$ in region $i$.

$X_{i} \quad$ Total number of experiences stores set for branding products in region $i$.

$Y_{i k} \quad$ The decision to set $\left(Y_{i k}=1\right)$ or not set $\left(Y_{i k}=0\right) k^{\text {th }}$ experience store in region $i$.

\subsection{Model 1}

In our study, model 1 is a simple model that does not incorporate the effect of learning curves. Before developing the experience store establishment model, a firm can obtain $D_{o i j}$ based on, for example, market surveys, which equals $b_{1 i j}-b_{2 i j} * P_{i j}$, i.e., 
$D_{o i j}\left(P_{i j}\right)=\left\{\begin{array}{lc}b_{1 i j}-b_{2 i j} P_{i j} & \text { if } \quad P_{i j} \leq \frac{b_{1 i j}}{b_{2 i j}} \\ 0 & \text { otherwise }\end{array}\right.$

The $D_{a i j}$, demand after building experience stores, equals $b_{1 i j}-b_{2 i j} * P_{i j}+c_{1 i j} * X_{i}-c_{2 i j} *\left(X_{i}\right)^{2}$, which is nonlinear (concave) in the number of experience stores. This is due to the above assumptions. Also, as experience stores may enhance the brand image, we treat product prices as decision variables (though, in our case studies, product prices are fixed as suggested by firms). Hence, we can model the decision problem of how many experience stores to establish as follows:

Maximize $\quad \pi=\sum_{i=1}^{m} \sum_{j=1}^{n}\left[P_{i j} D_{a i j}-U C_{j} * D_{a i j}\right]-\sum_{i=1}^{m} T F C_{i} * X_{i}$

Subject to:

$D_{a i j}=b_{1 i j}-b_{2 i j} P_{i j}+c_{1 i j} X_{i}-c_{2 i j}\left(X_{i}\right)^{2} \quad j=1, \cdots, n ; i=1, \cdots, m$

$X_{i} \leq r_{i} \quad i=1, \cdots, m$

$X_{i} \geq 0$, integer, $\forall i$

\subsection{Model 2}

Model 2 is a decision model for establishing experience stores incorporating the learning effect. Lieberman (1987) defined the learning effect: $y=a x^{-b}$ where

$y$ Cost of producing the $X^{\text {th }}$ unit.

a Cost of producing the first unit.

$x$ Cumulative number of units produced.

$b$ Parameter measuring the effect of learning as output increases.

As explained in Section 1, we observe that the cost of establishing an additional experience store may decrease as more stores are built. Hence, we apply the above learning concept to model the experience store establishment. The $T F C_{i k}$, estimated cost of establishing $k^{\text {th }}$ experience store in region $i$, will decrease as an increasing number of experience stores are established in a region. The values of $\alpha_{i}$ and $\beta_{i}$ in the first constraint are estimated by a firm. The second constraint is due to the fact that if a firm does not build $k^{\text {th }}$ experience store in region $i$, it will not build $(k+1)^{\text {th }}$ experience store in that region. Accordingly, model 2 is given by 
Maximize $\quad \pi=\sum_{i=1}^{m} \sum_{j=1}^{n}\left[P_{i j} D_{a i j}-U C_{j} * D_{a i j}\right]-\sum_{i=1}^{m} \sum_{k=1}^{r_{i}} T F C_{i k} * Y_{i k}$

Subject to:

$$
\begin{aligned}
& T F C_{i k}=\alpha_{i}\left(k Y_{i k}\right)^{-\beta_{i}} \quad k=1, \cdots, r_{i} \\
& Y_{i(k+1)} \leq Y_{i k} \quad k=1, \cdots r_{i}, i=1, \cdots, m \\
& D_{a i j}=b_{1 i j}-b_{2 i j} P_{i j}+c_{1 i j} X_{i}-c_{2 i j}\left(X_{i}\right)^{2} \quad j=1, \cdots n ; i=1, \cdots, m \\
& X_{i}=\sum_{k=1}^{r_{i}} Y_{i k} \quad i=1, \cdots, m \\
& X_{i} \geq 0, \text { integer, } \forall i \\
& Y_{i k} \in\{0,1\}, \forall i, k
\end{aligned}
$$

\subsection{Model 3}

It is possible that a firm establishes at most one experience store in each region. Model 3 considers this case. Now, $Y_{i k}=1$ if an experience store at instant (order) $k$ is open in region $i$, and $T F C_{i}$ is divided into two components: $T F C_{i}$ and $E T C_{i}$. In practice, the various costs of experience store establishment include land and building costs (rented or purchased), interior design costs (high quality decoration with high material costs), education and training costs, and employee costs. $T F C_{i}$ is now defined as the cost (such as land, building and rental cost) of establishing an experience store in region $i$, which is difficult to reduce (due to traffic convenience and a large space required). However, the store design, interior cost, and education and training cost in region $i$, which comprise $E T C_{i}$, may be reduced through a comprehensive education system and specific guidelines. $E T C_{i}$ suitably describes the learning effect and may be thought of as the cost of operating an experience store in region $i$, i.e., $E T C_{i}=\alpha_{i}\left(\sum_{1 \leq k \leq m} k Y_{i k}\right)^{-\beta_{i}}$, where $\alpha_{i}$ is the cost of establishing the first experience store in region $i$, while $\beta_{i}$ measures the rate of the decrease in $E T C_{i}$ as an experience store in other regions is built. ETC is the sum of $E T C_{i}$. Moreover, we need to impose two additional constraints below: constraints (1) mean that only one experience store can be open at instant $k$. Constraints (2) imply that at most one experience store can be open at any region. Thus, the number of experience stores built in region $i$ is $X_{i}=\sum_{1 \leq k \leq m} Y_{i k}$. Hence, model 3 can be expressed by 
Maximize $\quad \pi=\sum_{i=1}^{m} \sum_{j=1}^{n}\left[P_{j} D_{a i j}-U C_{j} * D_{a i j}\right]-\sum_{i=1}^{m}\left(T F C_{i} * X_{i}\right)+E T C$

Subject to:

$$
\begin{aligned}
& E T C_{i}=\alpha_{i}\left(\sum_{1 \leq k \leq m} k Y_{i k}\right)^{-\beta_{i}} \quad i=1, \cdots, m \\
& E T C=\sum_{i=1}^{m} E T C_{i} \\
& X_{i}=\sum_{1 \leq k \leq m} Y_{i k} \\
& D_{a i j}=b_{1 i j}-b_{2 i j} P_{j}+c_{1 i j} X_{i}-c_{2 i j}\left(X_{i}\right)^{2} \quad j=1, \cdots, n ; i=1, \cdots, m \\
& X_{i} \geq 0, \text { integer }, \forall i \\
& \sum_{1 \leq i \leq m} Y_{i k} \leq 1, \quad k=1, \cdots, m \\
& \sum_{1 \leq k \leq m} Y_{i k} \leq 1, \quad i=1, \cdots, m
\end{aligned}
$$

In our study, model 2 involves a sequential establishment process (as indicated by the second constraint) where the learning effect is shown as a reduction in the establishment cost, while model 1 represents a situation equivalent to the simultaneous establishment of facilities. In model 3, a firm establishes, at most, one experience store in a region. Hence, depending on the situation faced when establishing experience stores, a firm can use model 1, model 2 or model 3 for its establishment decision. The proposed model architecture is depicted in Figure 1.

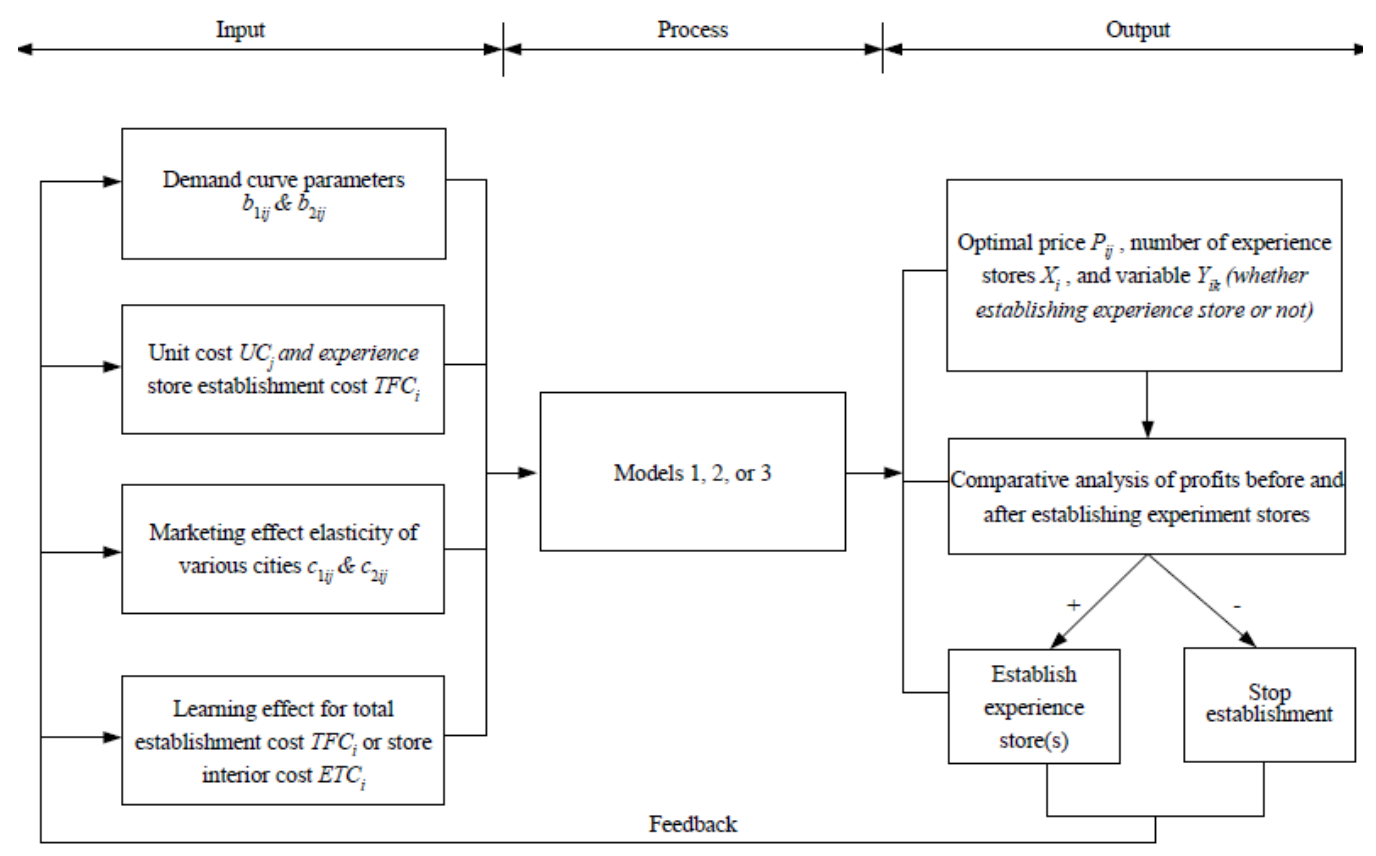

Figure 1. Proposed models' architecture 


\section{Case Studies}

The current trend of Taiwan manufacturers is to build experience stores to enhance the marketing effect and business performance. Taiwan industry examples of experience stores established include farm producers, staple goods producers (e.g. soy-bean sauce), and traditional and consumer-end industries. The decision-making process associated with Taiwan manufacturers for building experience stores is often managed by an investment or marketing team, and then approved by the chief of the firms. To validate experience store establishment models, interviews were conducted with the general manager of BlueApple (GroundJay Digi-Tec: Apple Taiwan agency) and with the distribution director of Amway Taiwan Company Limited. Interviews were conducted from 2007 to 2010. The two cases are very different. In the Apple case, the stores play both the function of selling and experience. Thus, analyzing the marketing effect of experience stores is very important. In the Amway case, the main selling channel is through recruitments. Hence, the main goal of Amway for building experience stores is to increase new recruits.

\subsection{Case A}

The Apple Store is a chain of retail stores owned and operated by Apple Inc., dealing in computers and consumer electronics. Beginning in 2000, BlueApple became the first agency to directly import Apple computer products for sale in Taiwan. Later, as BlueApple recognized that letting consumers touch, experience and learn how to operate Apple computer products would be helpful, it started to establish "Apple Centers" in order to increase profits. The general manager of BlueApple, Mr. Zhang, has expressed that the establishment of experience stores was originally a "trial and error" process (Zhang, 2009), which is in large part due to the fact that Apple computers have professional features - in the past, only prosumers (professional consumers) bought Apple computer products. BlueApple established Apple experience stores that followed the Apple guidelines about store design and merchandise placement. After the experience of the establishment process accumulated and the operation of Apple Centers improved, the building schedule and establishment decision of an Apple Center can be done quickly (Zhang, 2009).

There are 25 major cities in Taiwan, and in general, northern Taiwan is wealthier than southern Taiwan. BlueApple originally established ten experience stores in Taiwan, including four in Taipei, one in Hsinchu, one in Taichung, two in Tainan, and two in Kaohsiung. These cities were chosen based on their large populations. BlueApple earns fixed gross profits from sales of Apple products. Regarding the proposed models, Mr. Zhang suggested fixing product prices $\left(P_{j}\right)$. BlueApple also adjusted the experience store establishment based on profit performance. If the monthly sales volume did not exceed NT\$ 3 million dollars (the break-even point), then BlueApple withdrew from that market and closed the experience store. After several years of operation, there are now several Apple centers in Taiwan. Table 1 shows the current demand distribution of Apple branding products in the Taiwan market, as suggested by Mr. Zhang (Zhang, 2010) and compiled by the authors.

Table 2 lists the optimal solution derived for BlueApple experience stores via model 1. The various store rental costs and operating costs determine the values of $T F C_{i}$. Rents in Taipei 
are expensive, but are relatively lower in cities like Taichung, Tainan, and Kaohsiung. Therefore, we set various values of $T F C_{i}$ in order to find the $X_{i}$ solution. Considering the learning effect, Mr. Zhang agreed that the first experience store in a given city often did not attain economic efficiency; but, as the number of experience stores increased, the costs associated with employee training, store establishment, design, and interior design decreased. Table 3 gives the optimal solution based on model 2, and suggests that BuleApple could establish one more experience store in Hsinchu and Taichung, respectively, and one experience store in Tainan. Apple has built a unique version of the store design, operating courses, and employee education system. While the guidelines and employee education courses are provided by the parent firm, adjusting them to local conditions in various cities is important. Experience stores usually can be up and running in a short period of time, once the right establishment decisions are made.

Table 1. Demand situations of the BlueApple branding products in Taiwan (unit: NT\$)

\begin{tabular}{|c|c|c|c|c|c|c|}
\hline \multirow{2}{*}{ Region } & \multirow{2}{*}{ Brand } & \multirow{2}{*}{$\begin{array}{l}\text { City features/ } \\
\text { Consumer features }\end{array}$} & \multicolumn{2}{|c|}{ Demand situation 1} & \multicolumn{2}{|c|}{ Demand situation 2} \\
\hline & & & $P_{1}$ & $D_{1}$ & $P_{2}$ & $D_{2}$ \\
\hline \multirow{2}{*}{ Taipei } & iMac & High income & 33,000 & 7,500 & 3,6000 & 6,000 \\
\hline & iPod & Prosumer and consumer & 8,000 & 20,000 & 9,000 & 16,000 \\
\hline \multirow{2}{*}{ Hsinchu } & iMac & High income & 33,000 & 4,500 & 36,000 & 3,500 \\
\hline & iPod & Prosumer and consumer & 8,000 & 8,000 & 9,000 & 5,500 \\
\hline \multirow{2}{*}{ Taichung } & iMac & Middle income & 33,000 & 5,000 & 36,000 & 4,250 \\
\hline & iPod & Prosumer and consumer & 8,000 & 8,000 & 9,000 & 7,000 \\
\hline \multirow{2}{*}{ Tainan } & iMac & Middle income & 33,000 & 3,500 & 36,000 & 3,000 \\
\hline & iPod & Prosumer and consumer & 8,000 & 6,500 & 9,000 & 5,000 \\
\hline \multirow{2}{*}{ Kaohsiung } & iMac & Middle income & 33,000 & 3,000 & 36,000 & 2,250 \\
\hline & iPod & Prosumer and consumer & 8,000 & 6,500 & 9,000 & 5,000 \\
\hline
\end{tabular}

Note: Data was taken from the interview with the general manager of BlueApple Company Limited. 
Table 2. Optimal solution derived for BlueApple using Excel software (unit: NT\$)

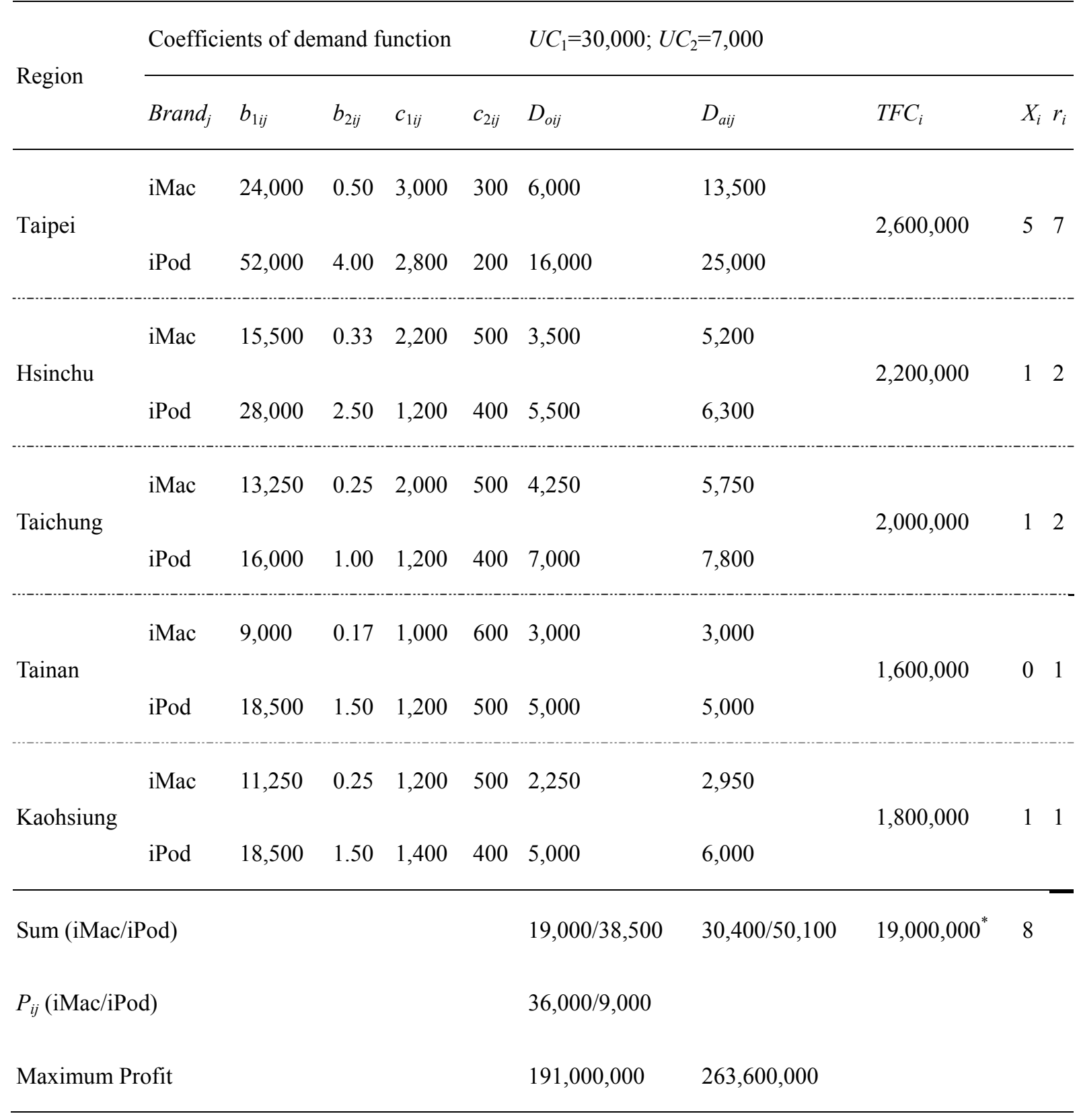

Note: Data was given by Mr. Zhang and compiled by the authors. ${ }^{*}=\Sigma\left(T F C_{i}{ }^{*} X_{i}\right)$. 
Table 3. Optimal solution derived for BlueApple using Lingo and Excel software (unit: NT\$)

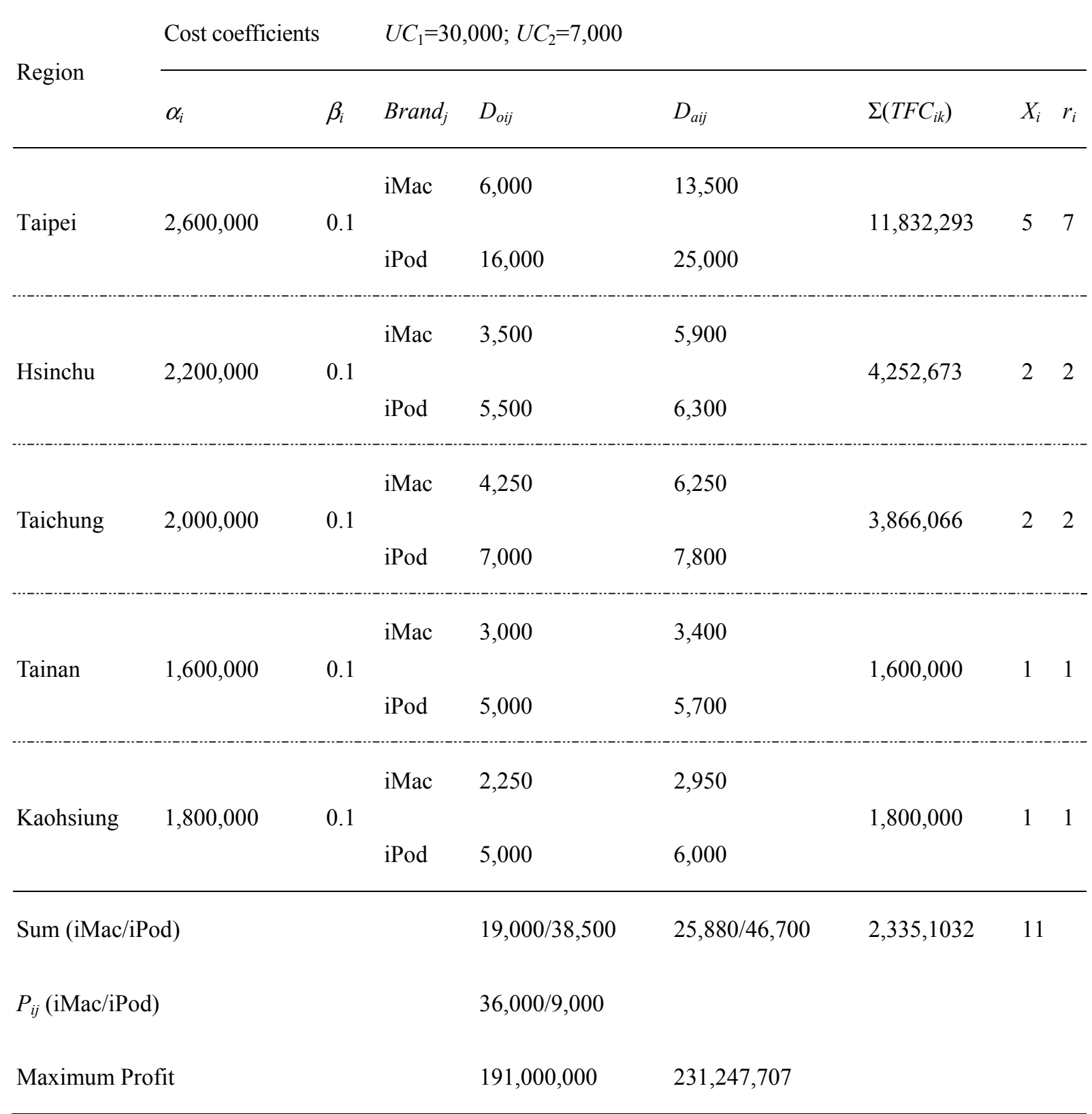

Note: Data was given by Mr. Zhang and compiled by the authors. Based on model 2, the maximum profit and experience store establishment costs are computed using the values of $X_{i}$, $P_{i j}, D_{a i j}$, and $T F C_{i k}$. Also, we obtain from the value of $\alpha_{i}$ and $\beta_{i}$ that $T F C_{11}=2,600,000$; $T F C_{12}=2,425,886 ; T F C_{13}=2,329,492 ; T F C_{14}=2,263,431 ; T F C_{15}=2,213,484 ; T F C_{21}=2,200,000$; $T F C_{22}=2,052,673 ; \quad T F C_{31}=2,000,000 ; \quad T F C_{32}=1,866,066 ; \quad T F C_{41}=1,600,000$; $T F C_{51}=1,800,000$.

\subsection{Case B}

Established in November 1982, Taiwan Amway is one of the leading direct sales corporations in Taiwan, offering products through its island-wide network of over 200,000 distributors. 
Annual sales of Taiwan Amway reached NT\$6.6 billion for the fiscal year ending August 31, 2005. The Taoyuan logistics center of Taiwan Amway was a pick-up center focusing on products prior to 2001. From 2001 to 2004, it was remodeled as a service center. After 2004, Taiwan Amway repositioned the Taoyuan center as an experience center. Distribution director Huang (2007) said that the Taoyuan center was the first to apply an experiential marketing strategy in the Taiwan logistics industry. It combined experiential marketing, logistics, and warehouse functions into one experience plaza. In this plaza, automated logistics equipment replaced human logistics workers who were transferred to other service departments, such as the call center and the coffee bar. After the success of the Taoyuan center, other Taiwan Amway experience plazas were established in remodeled facilities or new locations.

Taiwan Amway is committed to supporting their direct distributors. Main activities of Taiwan Amway experience plazas include: increasing recruits, supporting brand reputation, and improving service quality. Interior design of experience plazas focuses on success stories, brand reputation (showrooms, product stores, historical halls, and business opportunity sections) and experience sharing places such as $\mathrm{R} \& \mathrm{~J}$ coffee. These experience plazas enable distributors to introduce the Amway history, philosophy, and products easily and confidently. The major function of experience plazas is to attract recruits instead of final customers. Director Huang said that there was a $41 \%$ growth in recruitment, and that total sales nearly doubled after the establishment of the Taoyuan, Taipei, and Kaohsiung experience plazas. For our models, since Taiwan Amway is guided by American Amway, Director Huang suggested that the product price $P_{j}$ be fixed. She expressed that Taiwan Amway only establishes one experience center in each region; thus, model 3 is more appropriate to apply in Amway case. She also provided the current demand distribution of two Amway brand products (Espring-diverter and Girdle-long) in the Taiwan market, as shown in Table 4. For model simplification, we assume that more recruits mean more sales, denoted by $D_{a i j}$ (thus, we do not need a new variable to represent recruits).

Table 5 gives the optimal solution derived for Taiwan Amway experience plazas. The total sales of Taiwan Amway increased dramatically after the establishment of experience plazas. However, because of its commitment to a multi-level marketing role, Taiwan Amway discourages the development of retail stores invested and built by distributors. Since experience plazas only play an intermediary and marketing support role for distributors, channel conflicts between Taiwan Amway and its distributors have not occurred. On the other hand, Taiwan Amway has strengthened the loyalty of distributors by implementing an experiential marketing strategy. With the establishment of experience plazas, Taiwan Amway successfully improved consumer trust and favor on its products. 
Table 4. Demand situations of Taiwan Amway branding products in Taiwan (unit: NT\$)

\begin{tabular}{|c|c|c|c|c|c|c|}
\hline \multirow{2}{*}{ Region } & \multirow{2}{*}{ Product Brand } & \multirow{2}{*}{$\begin{array}{l}\text { City features/ } \\
\text { Consumer features }\end{array}$} & \multicolumn{2}{|c|}{ Demand situation 1} & \multicolumn{2}{|c|}{ Demand situation 2} \\
\hline & & & $P_{1}$ & $D_{1}$ & $P_{2}$ & $D_{2}$ \\
\hline \multirow{2}{*}{ Taipei } & ESPRING & High income & 28,000 & 7,500 & 31,000 & 6,000 \\
\hline & GIRDLE & Distributors and members & 2,800 & 20,000 & 3,300 & 16,000 \\
\hline \multirow{2}{*}{ Taichung } & ESPRING & High income & 28,000 & 4,500 & 31,000 & 3,500 \\
\hline & GIRDLE & Distributors and members & 2,800 & 8,000 & 3,300 & 5,500 \\
\hline \multirow{2}{*}{ Tainan } & ESPRING & Middle income & 28,000 & 4,000 & 31,000 & 3,250 \\
\hline & GIRDLE & Distributors and members & 2,800 & 6,000 & 3,300 & 4,000 \\
\hline \multirow{2}{*}{ Kaohsiung } & ESPRING & Middle income & 28,000 & 3,500 & 31,000 & 3,000 \\
\hline & GIRDLE & Distributors and members & 2,800 & 6,500 & 3,300 & 5,000 \\
\hline \multirow{2}{*}{ Taitung } & ESPRING & Low income & 28,000 & 600 & 31,000 & 1,200 \\
\hline & GIRDLE & Distributors and members & 2,800 & 1000 & 3,300 & 2,000 \\
\hline
\end{tabular}

Note: Data was from the interview with the distribution division director of Amway Taiwan Company Limited and compiled by the authors. 
Table 5. Optimal solution derived for Taiwan Amway using Excel (unit: NT\$)

$$
U C_{1}=10,000 ; U C_{2}=1,000
$$

TFC

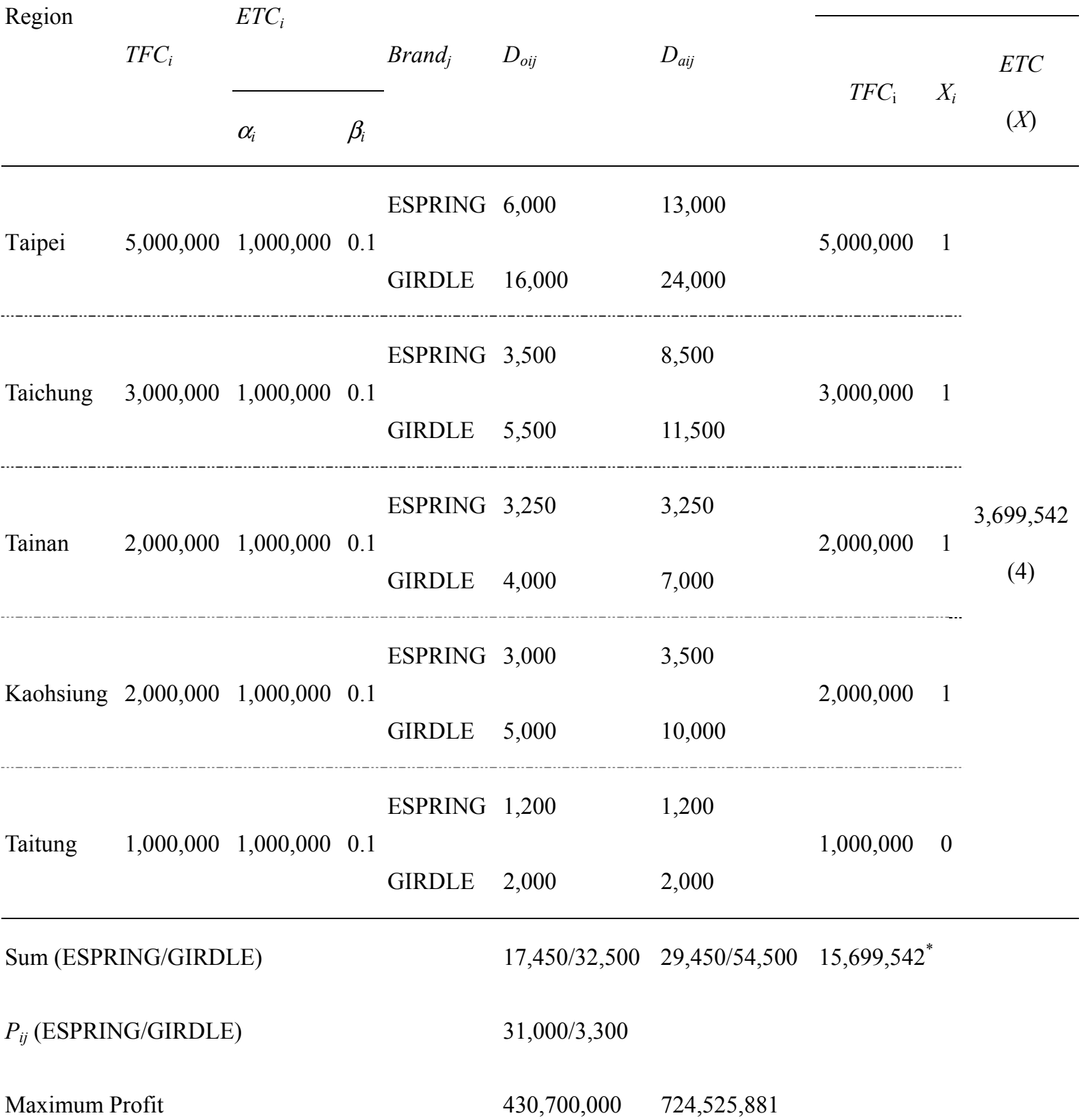

Note: Data was from the interview with the distribution division director of Amway Taiwan Company Limited and compiled by the authors. Based on model 3, the maximum profit and the establishment costs of experience stores are computed using the value of $X_{i}, P_{i j}, D_{a i j}, T F C_{i}$ and $E T C_{i}$. The $E T C$ costs of experience stores in five cities are obtained as follows: $E T C_{1}=1,000,000 ; E T C_{2}=933,033 ; E T C_{3}=895,959 ; E T C_{4}=870,550 .^{*}=\Sigma T F C_{i}+E T C$. 


\section{Discussion and Conclusion}

Location-based and strategic scope decision making by managers are frequently two of the most poorly understood and articulated processes. This dynamic notion of investment potential fits with the everyday experiences of retail organizations (Clarke, Bennison, \& Pal, 1997). In this paper, we clarify the specific characteristics of experience stores as compared to traditional retail stores and use integer programming to model the experience store establishment decision. Two case studies provided have helped to clarify the concepts underlying our models, though the purpose and operation environment of experience stores established by Apple and Amway are different. The case studies showed that the experience values and investment purposes of experience stores for the various markets associated with these two firms are quite different. Apple is well known for its industry-changing innovations and attractive designs, and has a clear idea of what people's experiences with its products should consist of (Gelder, 2005). Compared to Taiwan Amway, which is supported by its parent company, BlueApple is operating with high operating costs (without its parent company's support). However, thanks to large sales volumes originating from successful experience stores and vivid branding image, BlueApple has generated greater profits. Another aspect, Taiwan Amway has also increased both sales and recruits via the establishment of experience plazas, and avoided channel conflicts among its multi-level distributors, while establishing membership and reward systems to support its distributors.

From the results of this paper, we may summarize the conclusions as follows. First, experience stores can be a marketing tool for promoting a firm's products and image, though its position compared to general retail stores needs to be clarified. Second, the design and operation of experience stores should be carefully planned to ensure service quality and cost reductions. The learning curve concept (including employee learning and training) may be used to drive down the costs of establishing and operating experience stores. Third, understanding consumer characteristics and city features is helpful when choosing store allocation. Fourth, paying attention to agencies and dealers to reduce channel conflicts is necessary. Through the promotion and marketing effect of experience stores, performance of other distribution channels may be also improved. In order to simplify the experience store location models, the variables used in our models underwent a complex model transformation. Two case studies provided by the respondents have verified the concepts underlying our models. Table 6 shows a comparison of store establishment and operations derived from the two cases.

The limitation of this paper is that some elements of the proposed models are really simplified. For example, it is assumed that the impact of the number of experience stores on demand is independent of sales prices. Also, if several experience stores are to be built in the same region, it is assumed that they will be quite dispersed geographically to attain the marketing effect (they certainly will not be located side by side); the issue of the specific location of experience stores is not examined in this paper. Nevertheless, the proposed models still provide some important marketing concepts and implications for manufacturers, could be a significant contribution to existing research on retail store location. The two cases considered also may be used to test different or improved versions of the models. Future 
research is welcome to further clarify the model elements and strengthen their applicability to experience store establishment decision.

Table 6. Characteristics comparisons of store establishments and operations via two case studies

\begin{tabular}{|c|c|c|c|}
\hline \multirow{3}{*}{ Characteristics } & \multicolumn{2}{|r|}{ Apple } & \multirow{3}{*}{$\begin{array}{c}\text { Amway } \\
\text { Taiwan Amway }\end{array}$} \\
\hline & Other & BlueApple & \\
\hline & agency stores & experience stores & \\
\hline Product categories & Less categories & More categories & All categories \\
\hline Targeted customers & Prosumers & Consumers & Recruitments \\
\hline $\begin{array}{l}\text { Product knowledge of } \\
\text { customers }\end{array}$ & Middle or high & Low & Low \\
\hline $\begin{array}{l}\text { The degree of } \\
\text { interaction with } \\
\text { customers }\end{array}$ & Low or middle & High & High \\
\hline Location decision & Population & $\begin{array}{l}\text { Features of cities and } \\
\text { cooperative stores, and } \\
\text { consumer consumption level }\end{array}$ & $\begin{array}{l}\text { Features of cities, consumer } \\
\text { consumption level, and } \\
\text { traffic distance }\end{array}$ \\
\hline Establishment cost & Low & Middle & High \\
\hline $\begin{array}{l}\text { Learning curve effect: } \\
\text { training and store } \\
\text { design cost }\end{array}$ & $\begin{array}{l}\text { Depending on the } \\
\text { store number in the } \\
\text { same cities }\end{array}$ & Yes & Yes \\
\hline $\begin{array}{l}\text { Learning curve effect: } \\
\text { establishment cost }\end{array}$ & $\begin{array}{l}\text { Depending on the } \\
\text { store number in a city }\end{array}$ & $\begin{array}{l}\text { Depending on the store } \\
\text { number in a city }\end{array}$ & No \\
\hline Store image & None & $\begin{array}{l}\text { Uniformity with } \\
\text { characteristics }\end{array}$ & $\begin{array}{l}\text { Uniformity with } \\
\text { characteristics }\end{array}$ \\
\hline Store identification & Product sales & Product sales & Product sales \\
\hline & Service provider & Store image & Store image \\
\hline
\end{tabular}




\begin{tabular}{llll}
$\begin{array}{l}\text { Marketing effect of } \\
\text { store image }\end{array}$ & Low & High & High \\
\hline $\begin{array}{l}\text { Number of store } \\
\text { establishments }\end{array}$ & More stores & Less stores & Less stores \\
\hline $\begin{array}{l}\text { Channel competition } \\
\text { and cooperation }\end{array}$ & $\begin{array}{l}\text { Ruled by parent } \\
\text { company }\end{array}$ & Ruled by parent company & Cooperation \\
\hline Operation decision & Break-even point & Break-even point & \\
\hline
\end{tabular}

Note: Compiled by the authors.

\section{Acknowledgement}

The research is financed by Ministry of Scinece and Technology, Taiwan (R.O.C.). NSC: 98-2410-H-262-001.

\section{References}

Aboolian, R., Berman, O., \& Krass, D. (2007). Competitive facility location model with concave demand. European Journal of Operational Research, 181, 598-619. http://dx.doi.org/10.1016/j.ejor.2005.10.075

Bell, D., Ho, T. H., \& Tang, C. (1998). Determining Where to Shop: Fixed and Variable Costs of Shopping. Journal of Marketing Research, 35(August), 352-369. http://dx.doi.org/10.2307/3152033

Blattberg, R. C., \& Hoch, S. J. (1990). Database models and managerial intuition: 50\% Model $+50 \%$ Manager. Management Science, 36(August), 887-899. http://dx.doi.org/10.1287/mnsc.36.8.887

Brodie, R., \& Kluyver, C. (1984). Attraction versus linear and multiplicative market share models: An empirical evaluation. Journal of Marketing Research, 21, 194-201. http://dx.doi.org/10.2307/3151701

Chamber, S., \& Johnston, R. (2000). Experience curves in services: macro and micro level approaches. International Journal of Operations \& Production Management, 20(7), 842-859. http://dx.doi.org/10.1108/01443570010330757

Chaudhuri, A., \& Holbrook, M. B. (2002). Product-class effects on brand commitment and 
brand outcomes: The role of brand trust and brand affect. Journal of Brand Management, 10(1), 33-58. http://dx.doi.org/10.1057/palgrave.bm.2540100

Clarke, I., Bennison, D., \& Pal, J. (1997). Towards a contemporary perspective of retail location. International Journal of Retail \& Distribution Management, 25(2), 59-69. http://dx.doi.org/10.1108/09590559710160355

Dasci, A., \& Laporte, G. (2005). An analytical approach to the facility location and capacity acquisition problem under demand uncertainty. Journal of the Operational Research Society, 56(4), 397-405. http://dx.doi.org/10.1057/palgrave.jors.2601826

Durvasula, S., Sharma, S., \& Craig, A. J. (1992). STORELOC: A retail store location model based on managerial judgment. Journal of Retailing, 68(4), 420-444.

Farias, S. A., Aguiar, E. C., \& Melo, F. V. S. (2014). Store atmospherics and experiential marketing: A conceptual framework and research propositions for an extraordinary customer experience. International Business Research, 87-99. http://dx.doi.org/10.5539/ibr.v7n2p87

Gaur, V., \& Fisher, M. L. (2005). In-store experiments to determine the impact of price on sales. Production and Operations Management, 14(4), 377-387. http://dx.doi.org/10.1111/j.1937-5956.2005.tb00227.x

Gelder, S. V. (2005). The new imperatives for global branding: Strategy, creativity and leadership. Journal of Brand Management, 12(5), 395-404. http://dx.doi.org/10.1057/palgrave.bm.2540234

Ghosh, A., McLafferty, S., \& Craig, C. S. (1995), Multifacility retail networks. In: Drezner, Z (Eds), Facility Locations. Springer Verlag: Berlin, pp. 301-330. http://dx.doi.org/10.1007/978-1-4612-5355-6_15

Ghosh, A., Neslin, S., \& Shoemaker, R. (1984). A comparison of market share models and estimation procedures. Journal of Marketing Research, 21, 202-210. http://dx.doi.org/10.2307/3151702

Haig, R. M. (1926). Towards an understanding of the metropolis: II. The assignment of activities to areas in urban regions. Quarterly Journal of Economics, 40(May), 402-434. http://dx.doi.org/10.2307/1885172

Huang, G. (2007), Distribution Director of Distribution Division, Amway Taiwan Company Limited, Interview Notes for location choice and evaluation decision practices for experience stores establishment.

Huff, D. L. (1964). Defining and estimating a trade area. Journal of Marketing, 28, 34-38. http://dx.doi.org/10.2307/1249154

Kaufman, P. J., \& Rangan, V. K. (1990). A model for managing system conflict during franchise expansion. Journal of Retailing, 66(Summer), 155-173.

Küçükaydin, H., Aras, N., \& Altinel, I. K. (2011). A discrete competitive facility location 
model with variable attractiveness. Journal of Operational Research Society, 62(9), 1726-1741. http://dx.doi.org/10.1057/jors.2010.136

Lieberman, M. B. (1987). The learning curve, diffusion, and competitive strategy. Strategic Management Journal, 8(5), 441-452. http://dx.doi.org/10.1002/smj.4250080504

Mahajan, V, Sharma, S., \& Srinivas, D. (1985). An application of portfolio analysis for identifying attractive retail locations. Journal of Retailing, 61(Winter), 19-34.

Mathwicka. C., Malhotrab, N. K., \& Rigdonc, E. (2002). The effect of dynamic retail experiences on experiential perceptions of value: an Internet and catalog comparison. Journal of Retailing, 78, 51-60.

Naert, P. H., \& Weverbergh, M. (1981). On the prediction power of market share attraction models. Journal of Marketing Research, 21, 202-210. http://www.jstor.org/stable/3150949

Petkus Jr, E. (2004). Enhancing the application of experiential marketing in the arts. International Journal of Nonprofit and Voluntary Sector Marketing, 9(1), 49-56. http://dx.doi.org/10.1002/nvsm.232

Pine II, B. J., \& Gilmore, J. H. (1999). The Experience Economy. Harvard Business School Press: Boston.

Reilly, W. J. (1931),. The Law of Retail Gravitation. Knickerbocker Press: New York.

Roy, J. R., \& Thill, J. C. (2004). Spatial interaction modelling (pp. 339-361). Springer Berlin Heidelberg. http://dx.doi.org/10.1007/978-3-540-24807-1

Santos-Peñate, D. R., Suárez-Vega, R., \& Dorta-González, P. (2007). The Leader-Follower Location Model. Networks and Spatial Economics, 7(1), 45-61. http://dx.doi.org/10.1007/s11067-006-9007-2

Schneider, K., Johnson, J. C. Sleeper, B. J., \& Rodgers, W. C. (1998). A note on applying retail location models in franchise systems: A view from the trenches. The Journal of Consumer Marketing, 15(3), 290-296. http://dx.doi.org/10.1108/07363769810219152

Taylor, C. R., Franke, G. R., \& Bang, H. K. (2006). Use and effectiveness of billboards. Journal of Advertising, 35(4), 21-34. http://dx.doi.org/10.2753/JOA0091-3367350402

Tellis, G. J. (1988). Price elasticity of selective demand: A meta-analysis of econometric models of sales. Journal of Marketing Research, 25(4), 331-341. http://dx.doi.org/10.2307/3172944

Timor, M., \& Sipahi, S. (2005). Fast-Food restaurant selection factor evaluation by the analytic hierarchy process. The Business Review, 4, 161-167.

Urban, G. L. (1970). Sprinter MOD III: A model for the analysis of new frequently purchased consumer products. Operation Research, 18(September), 805-853. http://dx.doi.org/10.1287/opre.18.5.805

Vilcassim, N. J., Kadiyali, V., \& Chintagunta, P. K. (1999). Investigating dynamic multifirm 


\section{Macrothink}

Journal of Social Science Studies

ISSN 2329-9150 2015, Vol. 2, No. 1

market interactions in price and advertising. Management Science, 45(4), 499-518. http://dx.doi.org/10.1287/mnsc.45.4.499

Zhang, R. D. (2009; 2010), General Manager of company, GroundJay Digi-Tec, Interview Notes for location choice and evaluation decision practices for experience stores establishment. Taipei, Taiwan, R.O.C.

\section{Copyright Disclaimer}

Copyright reserved by the author(s).

This article is an open-access article distributed under the terms and conditions of the Creative Commons Attribution license (http://creativecommons.org/licenses/by/3.0/). 